\title{
Gray per Fraction
}

National Cancer Institute

\section{Source}

National Cancer Institute. Gray per Fraction. NCI Thesaurus. Code C159625.

A unit of absorbed radiation dose equal to the number of grays per fraction. 